\title{
Plastic Surgery Training: A Privilege and Honor
}

\author{
Sung Tack Kwon
}

Department of Plastic Surgery, Seoul National University College of Medicine, Seoul, Korea

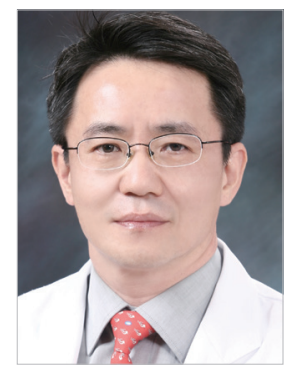

In this day and age, every aspect of society has already been commercialized. It seems that anything can be regarded as a commodity. Due to influences from many directions, medical practice has not been an exception, and in fact, it is sometimes a prime example of such commercialism. Physicians' open commercial advertising has gone beyond a social problem to become a media extravaganza. Many people have criticized these phenomena as if the medical doctors are the only group responsible. Even most physicians blame plastic surgeons as if we have committed the original sin. Because we must deal with underpayment from what the national health system does not cover and our work is a hot-button social issue, we have received the most attention. The more serious problem is that even we plastic surgeons often censure each other.

Aesthetic surgery profits from the ideology of a society that serves only vanity, youthfulness, and personal success-one that is losing sight of real values that can go beyond the immediate desires of patients. This is a social trend that no one can successfully resist. However, we find ourselves in this current situation and have a certain responsibility to try to reduce or reverse this vicious cycle; the huge expense for marketing, along with corrupt brokers for foreign patients, hiring non-specialist doctors, allocating little time for developing doctor-patient relationships, and many other factors together result in low-priced surgery that can never match our professional standards. These conflicts among physicians go beyond popular ethical issues. In light of all these issues, together with the disgraceful challenge of the prevalence of aesthetic surgeons without board certification in the specialty, we may assess the current situation as worsening and worry about losing our collective self-respect and eventually our professional identity.

Can ethics education help us to escape from this situation? We know that we cannot change the world; however, there may be something we have missed or neglected—something within our power to change, that is, our own professionalism. Perhaps there is some area of deficiency in plastic surgery training in professionalism and ethics. And this is not the ordinary need for professionalism common to other occupations; it is more significant and urgent. The surgeons who are training our residents must take their professional commitment seriously and show genuine care for both formal training and modeling ethics through their daily practice. Therefore, reform may involve plastic surgery residents as well as trainers. I would like to suggest that a curriculum on the "human factor" be added to the conventional training in professionalism. This curriculum should include the following:

(1) Pride and respect for the positive moral development of the trainee

This includes a program for contributing to society.

(2) Safety

Warning that any fault or neglect of common safety guidelines will not be tolerated cannot be overemphasized. A weekly seminar including previous problem cases should be routine.

(3) Improving the doctor-patient relationship Surgeons have certain duties they fulfil to maintain patients' trust. In addition, the patient-doctor re-interview and presentation is now recognized as another helpful tool. 
(4) Acknowledging reality: proper finance and implications of borrowing money

Recognizing reality in clinic management and finance will help us to understand how difficult it is to reduce financial risks.

(5) Reading assignments for recognizing social trends relevant to plastic surgery. e.g., two books per year).

Though our trainees are already adults with strong egos, reading other people's thoughts is the most effective way that they can maintain an understanding of the public perspective and build an interest in human well-being. This may lead them to make fewer social and ethical missteps.

Dr. Swanson has noted, "In our specialty, we have the amazing ability to often cure sources of unhappiness [1].” Our training is an amazing privilege to be honored by refusing to settle for something less than our ideals. To that point, with pride and honor, we need to think more carefully about our obligations to patients and society, including both the patient's benefits as well as safety.
Overcoming today's grave situation requires serious thinking and effort to train plastic surgeons with sophistication. While our professional society (the Korean Society of Plastic and Reconstructive Surgery) can propose specific programs, every trainer's passionate concern for training with exemplary practice is the most important and effective approach.

\section{REFERENCE}

1. Swanson E. The commercialization of plastic surgery. Aesthet Surg J 2013;33:1065-8.

Correspondence: Sung Tack Kwon

Department of Plastic Surgery, Seoul National University College of Medicine, 103 Daehak-ro,

Jongno-gu, Seoul 110-799, Korea

Tel: +82-2-2072-3759, Fax: +82-2-745-5986, E-mail: stk59@snu.ac.kr

No potential conflict of interest relevant to this article was reported.

Received: 17 Apr 2015 • Revised: 17 Apr 2015 • Accepted: 18 Apr 2015

pISSN: 2234-6163 • elSSN: 2234-6171

http://dx.doi.org/10.5999/aps.2015.42.3.265 • Arch Plast Surg 2015;42:265-266 